Revista Brasileira de Agricultura Irrigada v.9, nº.3, p. 171 - 182, 2015

ISSN 1982-7679 (On-line)

Fortaleza, CE, INOVAGRI - http://www.inovagri.org.br

DOI: $10.7127 /$ rbai.v9n300286

Protocolo 286.15 - 09/03/2015 Aprovado em 07/05/2015

\title{
TROCAS GASOSAS E FITOMASSA SECA DA CULTURA DO MELOEIRO IRRIGADO POR GOTEJAMENTO NAS CONDIÇÕES SEMIÁRIADAS DO NORDESTE
}

\author{
João Valdenor Pereira Filho ${ }^{1}$, Francisco Marcus Lima Bezerra ${ }^{2}$, Keivia Lino Chagas ${ }^{3}$, Tiago \\ Cavalcante da Silva ${ }^{3}$, Carmem Cristina Mareco de Sousa Pereira ${ }^{4}$
}

\begin{abstract}
RESUMO
O objetivo deste trabalho foi avaliar a fitomassa seca e as trocas gasosas e a produção de fitomassa do meloeiro rendilhado, variedade 'Imperial 45', sobre diferentes frequências de irrigação e adubação nitrogenada em diferentes épocas. $\mathrm{O}$ experimento foi conduzido na Fazenda experimental Vale do Curu, Pentecoste, CE, sob delineamento experimental em blocos casualizados com parcelas subdivididas, em esquema fatorial $6 \times 4$ e três repetições. Os tratamentos consistiram da combinação de seis frequências de irrigação, consideradas parcelas, que foram: 0,$5 ; 1,0 ; 2,0 ; 3,0 ; 4,0$ e 5,0 dias e nas subparcelas o efeito de quatro épocas de aplicação da adubação em cobertura de $90 \mathrm{~kg} \mathrm{ha}^{-1}$ de $\mathrm{N}$, sendo $\mathrm{N} 1: 100 \%$ aos 20 DAS (0-100-0-0); N2: 30\% na semeadura e 70\% aos 20 DAS (30-70-0-0); N3: $30 \%$ na semeadura, $30 \%$ aos 20 DAS e $40 \%$ aos 35 DAS (30-30-40-0) e N4: $20 \%$ na semeadura, $30 \%$ aos 20 DAS, $30 \%$ aos 35 DAS e $20 \%$ aos 50 DAS (20-30-30-20). O manejo da irrigação com frequência diária (F2) apresentou melhores valores para a condutância estomática, fotossíntese e transpiração, com uma adubação de $\mathrm{N}$ em cobertura aos 50 DAS. O déficit hídrico ocasionado entre duas irrigações na menor frequência de irrigação, assim como, a aplicação total em cobertura do $\mathrm{N}$ aos 20 DAS proporciona menores valores em todas as variáveis analisadas.
\end{abstract}

Palavras-chaves: manejo da irrigação; características fisiológicas; Cucumis melo L.; nitrogênio

\section{PHYSIOLOGICAL CHARACTERISTICS OF MUSKMELON AND BIOMASS SUBMITTED THE DIFFERENT IRRIGATION FREQUENCIES AND SPLIT NITROGEN FERTILIZATION}

\footnotetext{
${ }^{1}$ Doutorando em Engenharia Agrícola, Departamento de Engenharia Agrícola, Universidade Federal do Ceará, Fortaleza, Brasil, Campus do Pici, CCA/UFC, Av. Mister Hull, 2977, CEP 60455-760, Fortaleza, CE, email: joao_valdenor@hotmail.com

${ }^{2}$ Professor do Departamento de Engenharia Agrícola, Universidade Federal do Ceará, Fortaleza, Brasil, Campus do Pici, CCA/UFC, Fortaleza, CE, e-mail: mbezerra@ufc.br;

${ }^{3}$ Bolsista PIBIC/UFC, Departamento de Engenharia Agrícola, Universidade Federal do Ceará, Fortaleza, Brasil, Campus do Pici, CCA/UFC, Fortaleza, CE, e-mail: kei-via@hotmail.com; tiago.cavalcantesilva@ hotmail.com;

${ }^{4}$ Doutora em Engenharia Agrícola, Instituto Inovagri, Fortaleza, Ceará, Rua João Carvalho, 800, Fortaleza, CE, email: crismareco@hotmail.com
} 


\begin{abstract}
This study evaluated the physiological characteristics and behavior of the dry biomass production of muskmelon cultivated under different irrigation frequencies and splitting of nitrogen at different times. The experiment was conducted at Pentecoste, Ceará, Brazil, in a randomized blocks in a $6 \times 4$ factorial scheme, in split plots with three repetitions. The treatments were a combination of six irrigation frequencies, considered parcels, which were: $0.5 ; 1.0 ; 2.0 ; 3.0 ; 4.0$ and 5.0 days and the subplots the effect of four of fertilizer application times in coverage of $90 \mathrm{~kg} \mathrm{~N} \mathrm{ha}^{-1}: 100 \%$ at 20 days after sowing -DAS-(0-100-0-0); 30\% at sowing and $70 \%$ at 20 DAS (30-70-0-0); 30\% at sowing, $30 \%$ at 20 DAS and $40 \%$ at 35 DAS (30-30-40-0); $20 \%$ at sowing, $30 \%$ at 20 DAS, $30 \%$ at 35 DAS and $20 \%$ at 50 DAS (2030-30-20). Irrigation management on a daily basis (F2) showed better values for stomatal conductance, photosynthesis and transpiration, with a fertilizer $\mathrm{N}$ in coverage to $50 \mathrm{DAS}$. The water deficit caused between two irrigation in lower frequency of irrigation, as well as total coverage in the application of $\mathrm{N}$ at 20 DAS propitiated lower values of all variables.
\end{abstract}

Keywords: irrigation management; physiological characteristics; Cucumis melo L .; nitrogen

\section{INTRODUÇÃO}

A cultura do melão (Cucumis melo L.) possui grande importância socioeconômica para a região Nordeste do Brasil. Seu crescimento, desenvolvimento e produção são substancialmente afetados pelas condições climatológicas de uma região. Diante disto, diversas pesquisas tem sido realizadas visando o conhecimento morfofisiológico desta cultura, com vistas à otimização da eficiência do uso de água e aproveitamento das condições edafoclimáticas das áreas irrigadas. Sabe-se que o clima no Nordeste do Brasil apresenta aspectos muito favoráveis ao cultivo do meloeiro, principalmente devido à disponibilidade de energia. No entanto, oferece restrições quanto à distribuição espacial e temporal das chuvas, tornando a prática de irrigação indispensável para garantir ou otimizar a produção agrícola (Silva et al., 2005).

Suassuna et al. (2011) destacam que, tanto o excesso quanto o déficit hídrico, afetam o crescimento e desenvolvimento do meloeiro e que, por isso, o propósito da prática da irrigação é manter uma condição hídrica adequada dos vegetais, afim de garantir um bom desenvolvimento da cultura.

De acordo com Paiva et al. (2005), o decréscimo na disponibilidade de água no solo ocasiona queda no potencial da água nas folhas das plantas, levando à perda de turgescência e à redução da condutância estomática. A redução da taxa de assimilação de $\mathrm{CO}_{2}$ durante o estresse hídrico deve-se à redução na disponibilidade de $\mathrm{CO}_{2}$ no interior da folha, causada pelo fechamento dos estômatos em resposta à redução da disponibilidade de água no solo. Esse aumento da resistência à difusão gasosa e a diminuição na taxa de assimilação de $\mathrm{CO}_{2}$ determina menor perda de água por transpiração, além de poder afetar a fotossíntese.

Quanto ao manejo do nitrogênio em sistemas agrícolas, devem-se considerar todos os riscos ambientais envolvidos, uma vez que este nutriente está sujeito a elevadas perdas por erosão, lixiviação, desnitrificação e volatilização. Desta forma, o manejo ideal da adubação nitrogenada pode ser definido como sendo aquele que permite satisfazer à necessidade da cultura ao longo de seus diferentes estágios de desenvolvimento. Segundo Marenco e Lopes (2009), a disponibilidade de nutrientes minerais influencia indiretamente a capacidade fotossintética das plantas e, dentre todos os elementos, o nitrogênio é um dos que mais influenciam a fotossíntese, através da sua essencialidade para a formação das proteínas e das clorofilas. Isto posto, o objetivo deste trabalho foi avaliar a produção de fitomassa seca e as trocas gasosas do meloeiro rendilhado, variedade 'Imperial 45', sobre diferentes frequências de irrigação e adubação nitrogenada em diferentes épocas. 


\section{MATERIAL E MÉTODOS}

O experimento foi conduzido de julho a outubro de 2011, na Fazenda Experimental do Vale do Curu (FEVC), pertencente à Universidade Federal do Ceará, em Pentecoste, CE, entre os paralelos $3^{\circ} 45^{\prime}$ e $3^{\circ} 50^{\prime}$ de latitude Sul e os meridianos $39^{\circ} 15^{\prime}$ e $39^{\circ} 30^{\prime}$ de longitude Oeste, a uma altitude de $47 \mathrm{~m}$. O clima é classificado como BSw'h', caracterizado como tropical chuvoso. O solo da área experimental é classificado como Neossolo Flúvico, de textura franco arenosa na camada de 0 a $0,70 \mathrm{~m}$ (EMBRAPA, 1999). Os dados climatológicos estão apresentados na Tabela 1. As análises dos principais atributos químicos do solo da área experimental foram realizadas pelo Laboratório de Solos e Água, do Departamento de Ciências do Solo do CCA/UFC (Tabela 2).

Tabela 1 - Condições climáticas médias observadas durante o experimento. FEVC, Pentecoste, CE, 2011

\begin{tabular}{ccccc}
\hline \multirow{2}{*}{ Mês } & $\begin{array}{c}\text { Temp. } \\
\text { méd }\end{array}$ & UR & ETo & Precipitação \\
\cline { 3 - 5 } & ${ }^{\circ} \mathrm{C}$ & $(\%)$ & \multicolumn{2}{c}{$\mathrm{mm}$} \\
\hline Julho & 27,4 & 67 & 163,0 & 32,2 \\
Agosto & 30,4 & 57 & 244,9 & 0,0 \\
Setembro & 30,9 & 50 & 258,6 & 0,0 \\
Outubro & 30,9 & 50 & 258,6 & 0,0 \\
\hline
\end{tabular}

Temp. Méd-temperatura média; UR-umidade relativa; ETo-evapotranspiração de referência.

Tabela 2 - Atributos químicos do solo da área experimental. Pentecoste, CE, 2011.

\begin{tabular}{|c|c|c|c|c|c|c|c|}
\hline \multirow{2}{*}{$\begin{array}{c}\text { Camada } \\
(\mathrm{cm})\end{array}$} & Fósforo & Potássio & Sódio & \multirow{2}{*}{$\begin{array}{c}\mathrm{pH} \\
\left(\mathrm{H}_{2} \mathrm{O}\right)\end{array}$} & Cálcio & Magnésio & Alumínio \\
\hline & & $\left.\mathrm{mg} \mathrm{dm}^{-3}\right)$ & & & \multicolumn{3}{|c|}{$\left(\mathrm{cmol}_{\mathrm{c}} \mathrm{dm}^{-3}\right)$} \\
\hline $0-20$ & 78,00 & 515,00 & 73,00 & 7,2 & 4,80 & 3,70 & 0,00 \\
\hline $20-40$ & 56,00 & 246,00 & 4,50 & 7,2 & 4,00 & 0,00 & 70,00 \\
\hline
\end{tabular}

O preparo da área experimental iniciou-se com uma roçagem, seguida de uma gradagem e posteriormente a estas operações procedeu-se com o piqueteamento da área, demarcando ao longo da área experimental as medidas equivalentes das parcelas e subparcelas. A semeadura foi realizada diretamente no campo, obedecendo um espaçamento entre linhas de 1,8 $\mathrm{m}$ e de $0,5 \mathrm{~m}$ entre plantas. A adubação foi realizada com base na análise química do solo e na necessidade nutricional da cultura. Foram aplicados o equivalente a $90 \mathrm{~kg}$ de $\mathrm{N} \mathrm{ha}^{-1}, 80 \mathrm{~kg}$ de $\mathrm{P}_{2} \mathrm{O}_{5}$ ha $^{-1}$ (aplicado em fundação) e $90 \mathrm{~kg}$ de $\mathrm{K}_{2} \mathrm{O} \mathrm{ha}^{-1}$ (destes, $30 \mathrm{~kg} \mathrm{ha}^{-1}$ foram aplicados em fundação), tendo sido usado como fonte dos nutrientes a uréia, o superfosfato simples e o cloreto de potássio, respectivamente. Para suprir prováveis deficiências de micronutrientes foram fornecidos, $18 \mathrm{~g}$ de FTE BR 12 por cova, em fundação. Os $60 \mathrm{~kg} \mathrm{ha}^{-1}$ restantes do $\mathrm{K}_{2} \mathrm{O}$ foram distribuídos e aplicados, via fertirrigação, durante todo o ciclo da cultura aos $15,30,45 \mathrm{e}$
60 DAS, nas seguintes quantidades 5, 15, 25 e 15 $\mathrm{kg}$ de $\mathrm{K}_{2} \mathrm{O}$ ha $^{-1}$, respectivamente.

A área total ocupada pelo experimento foi de $1555,2 \mathrm{~m}^{2}$ (97,2 m x 16,0 m), constituído de 54 linhas de plantas.

O delineamento estatístico adotado foi o de blocos ao acaso com parcelas subdivididas, num esquema fatorial $6 \times 4$, com três repetições. Cada bloco era composto por 18 linhas de plantas, em que foram distribuídas as parcelas, 6 frequências de irrigação baseadas na evapotranspiração da cultura (ETc), sendo $\mathrm{F} 1$ = irrigação realizada duas vezes ao dia (manhã e tarde); F2 = irrigação diária (somente pela manhã); F3 = irrigação realizada a cada dois dias; F4 = irrigação realizada a cada três dias; $\mathrm{F} 5=$ irrigação realizada a cada quatro dias e F6 = irrigação realizada a cada cinco dias, consideradas parcelas. Cada parcela foi dividida em quatro partes e distribuída, ao acaso, as épocas de aplicação da adubação nitrogenada $\left(90 \mathrm{~kg} \mathrm{ha}^{-1}\right)$, consideradas as subparcelas, a saber, $\mathrm{N} 1=100 \%$ 
aos 20 dias após a semeadura DAS (0-100-0-0); $\mathrm{N} 2=30 \%$ na semeadura e $70 \%$ aos 20 DAS (30$70-0-0) ; \mathrm{N} 3=30 \%$ na semeadura, $30 \%$ aos 20 DAS e $40 \%$ aos 35 DAS (30-30-40-0); N4 = $20 \%$ na semeadura, $30 \%$ aos 20 DAS, $30 \%$ aos 35 DAS e $20 \%$ aos 50 DAS (20-30-30-20), caracterizando as subparcelas.

O método de irrigação adotado foi do tipo localizado, sendo o sistema por gotejamento; contendo 54 linhas laterais, sendo uma por fileira de planta; gotejadores tipo autocompensantes, modelo katif, com vazão de $3,75 \mathrm{~L} \mathrm{~h}^{-1}$ a uma pressão de serviço de $100 \mathrm{kPa}$. No período compreendido entre a semeadura até o estabelecimento da cultura (primeiros 15 DAS), a irrigação era feita com um tempo de aproximadamente 2 horas, de modo a manter um teor de umidade adequado para garantir uma boa germinação e desenvolvimento inicial das plantas.

Após os 15 DAS deu-se a diferenciação dos tratamentos, sendo o tempo de irrigação para cada tratamento calculado com base nas informações de: evapotranspiração da cultura, espaçamentos da cultura, percentagem de área molhada, coeficiente de uniformidade de aplicação e vazão do emissor (Eq. 1).

$$
T I=\frac{E T c\left(E T_{0} * k_{c}\right) * E_{1} * E_{2}}{C u * q_{e}} * P A M
$$

em que,

Ti - tempo de irrigação para cada tratamento em $\mathrm{h}$;

ETc - evapotranspiração da cultura em mm;

E1 e E2 - espaçamentos da cultura, entre plantas na linha e entre fileiras de plantas em $\mathrm{m}$;

PAM - percentagem de área molhada em decimal (valor adotado 0,40);

$\mathrm{C}_{\mathrm{u}}$ - coeficiente de uniformidade de aplicação em decimal (valor encontrado na avaliação do sistema 0,9);

$\mathrm{q}_{\mathrm{e}}$ - vazão média dos emissores em $\mathrm{L} \mathrm{h}^{-1}$.

Para a obtenção do coeficiente de ajuste do tanque (Kp) foi utilizada a Eq. 2, proposta por Snyder (1992), apresentada abaixo:

$$
k p=0,482+0,024 \ln (F)-0,000376 U+0,0045 U R
$$

em que,

F - tamanho da área de bordadura em m;

$\mathrm{U}$ - velocidade média do vento em $\mathrm{km} \mathrm{dia}^{-1}$;

UR - umidade relativa média do ar (\%).

Os dados climáticos necessários para o cálculo do coeficiente de ajuste do tanque $\left(\mathrm{k}_{\mathrm{p}}\right)$ foram obtidos mediante a média aritmética dos últimos cinco anos para os meses nos quais o experimento foi conduzido. Os valores do coeficiente de cultivo $\left(\mathrm{k}_{\mathrm{c}}\right)$ utilizados nesta pesquisa para obtenção dos dados referentes a evapotranspiração da cultura (ETc) foram baseados nos dados apresentados por Marouelli et al. (1994), que trabalhando com a cultura do melão encontraram os seguintes valores: 0,5 (022 dias); 0,8 (23-40 dias); 1,05 (41-58 dias) e 0,75 (59-final do ciclo).

As características fisiológicas foram avaliadas aos 55 DAS e efetuadas medições de fotossíntese líquida, transpiração e condutância estomática. Essas medidas foram feitas em folhas completamente maduras, a quinta a partir do ápice da haste principal da cultura, por meio de um analisador de gás infravermelho (IRGA, ADC System). As leituras foram realizadas entre 9 e $11 \mathrm{~h}$ sob as condições climáticas reinantes na área experimental. Para obtenção da matéria seca total, foi realizado o corte das plantas de cada subparcela rente à superfície do solo e separando-se as amostras em limbo foliar e hastes. Após a obtenção da massa fresca, amostras homogêneas de cada parte da planta foram acondicionadas em sacos de papel, secadas em estufa a $60{ }^{\circ} \mathrm{C}$ até peso constante e pesadas para a obtenção do teor de matéria seca.

Os dados das variáveis avaliadas foram submetidos à análise de variância pelo teste $\mathrm{F}$ a 1 e 5\% de probabilidade. Quando verificado efeito significativo na análise de variância, os dados obtidos nos diferentes tratamentos de natureza qualitativa foram comparadas através do teste de Tukey em nível de 1 e 5\% de probabilidade, utilizando-se para isso o software para análises estatísticas ASSISTAT 7.6 Beta (SILVA, 2012). 


\section{RESULTADOS E DISCUSSÃO}

$\mathrm{O}$ resumo da análise de variância para as variáveis de condutância estomática (CES), fotossíntese (FOT), transpiração (TRA), matéria seca das folhas (MSF), matéria seca das hastes (MSH) e matéria seca total (MST) estão apresentados na Tabela 3. Observa-se que a interação entre os fatores frequência de irrigação (F) e parcelamento da adubação nitrogenada em diferentes épocas $(\mathrm{N})$ não foi significativo para nenhuma das variáveis estudadas, no entanto, houve efeito isolado da frequência de irrigação para todas as variáveis avaliadas, e da adubação nitrogenada para as variáveis CES, TRA, MSF, MSH e MST.

Tabela 3 - Análise de variância para a condutância estomática (CES), fotossíntese (FOT), transpiração (TRA), matéria seca das folhas (MSF), matéria seca das hastes (MSH) e matéria seca total (MST) do meloeiro cultivado sob diferentes frequências de irrigação e ao parcelamento da adubação nitrogenada em diferentes épocas ${ }^{1}$

\begin{tabular}{cccccccc}
\hline \multirow{2}{*}{ F.V } & \multirow{2}{*}{ GL } & \multicolumn{7}{c}{ Teste F } \\
\cline { 3 - 7 } & & CES & FOT & TRA & MSF & MSH & MST \\
\hline Blocos & 2 & $0,001^{\text {ns }}$ & $15,795^{\text {ns }}$ & $0,619^{\text {ns }}$ & $160,76^{\text {ns }}$ & $69,10^{\text {ns }}$ & $279,17^{\text {ns }}$ \\
Frequência (F) & 5 & $0,130^{* *}$ & $161,477^{* *}$ & $15,973^{* *}$ & $6276,39^{* *}$ & $1394,72^{* *}$ & $11608,33^{* *}$ \\
Nitrogênio (N) & 3 & $0,022^{* *}$ & $8,287^{\text {ns }}$ & $10,076^{* *}$ & $2983,33^{* *}$ & $2132,41^{* *}$ & $8202,78^{* *}$ \\
F x N & 15 & $0,002^{\text {ns }}$ & $4,507^{\text {ns }}$ & $0,726^{\text {ns }}$ & $69,72^{\text {ns }}$ & $24,91^{\text {ns }}$ & $81,11^{\text {ns }}$ \\
Resíduo & 36 & 0,003 & 6,967 & 0,374 & 67,82 & 56,02 & 150,69 \\
\hline CV $(\%)$ & - & 17,98 & 11,71 & 7,34 & 14,59 & 16,23 & 10,30 \\
\hline
\end{tabular}

${ }^{1 * *}$ significativo a nível de 0,01 de probabilidade $(\mathrm{p}<0,01)$; ${ }^{*}$ significativo a nível de 0,05 de probabilidade $(0,01 \leq \mathrm{p}<0,05) \mathrm{e}$ ${ }^{\mathrm{ns}}$ não significativo $(\mathrm{p} \leq 0,05)$.

$\mathrm{Na}$ Tabela 4 são apresentados os valores médios das variáveis condutância estomática (CES), fotossíntese (FOT), transpiração (TRA), matéria seca das folhas (MSF), matéria seca das hastes (MSH) e matéria seca total (MST) submetidas a diferentes frequências de irrigação.

Tabela 4 - Condutância estomática (CES), fotossíntese (FOT), transpiração (TRA), matéria seca das folhas (MSF), matéria seca das hastes (MSH) e matéria seca total (MST) do meloeiro cultivado sob diferentes frequências de irrigação*

\begin{tabular}{|c|c|c|c|c|c|c|}
\hline \multirow{2}{*}{$\begin{array}{l}\text { Frequência de } \\
\text { Irrigação }\end{array}$} & \multirow{2}{*}{$\begin{array}{c}\text { CES } \\
\left(\mathrm{mol} \cdot \mathrm{m}^{-2} \cdot \mathrm{s}^{-1}\right)\end{array}$} & \multirow{2}{*}{$\begin{array}{c}\text { FOT } \\
\left(\mu \mathrm{mol} \cdot \mathrm{m}^{-2} \cdot \mathrm{s}^{-1}\right)\end{array}$} & \multirow{2}{*}{$\begin{array}{c}\text { TRA } \\
\left(\mathrm{mmol} \cdot \mathrm{m}^{-2} \cdot \mathrm{s}^{-1}\right)\end{array}$} & MSF & MSH & MST \\
\hline & & & & \multicolumn{3}{|c|}{$\left(\right.$ g.planta $\left.{ }^{-1}\right)$} \\
\hline F1 & $0,402 \mathrm{~b}$ & $26,03 \mathrm{a}$ & $9,38 \mathrm{ab}$ & $96,67 \mathrm{a}$ & $59,58 \mathrm{a}$ & $156,25 \mathrm{a}$ \\
\hline $\mathrm{F} 2$ & $0,477 \mathrm{a}$ & $26,33 \mathrm{a}$ & $9,71 \mathrm{a}$ & $95,83 \mathrm{a}$ & $55,83 \mathrm{a}$ & $151,66 \mathrm{a}$ \\
\hline F3 & $0,368 \mathrm{~b}$ & $24,91 \mathrm{a}$ & $8,72 \mathrm{abc}$ & 87,08 a & $48,33 \mathrm{~b}$ & $135,41 \mathrm{a}$ \\
\hline F4 & $0,263 \mathrm{c}$ & $20,93 \mathrm{~b}$ & $8,01 \mathrm{bcd}$ & $60,83 \mathrm{~b}$ & $44,58 \mathrm{~b}$ & $105,41 \mathrm{~b}$ \\
\hline F5 & $0,242 \mathrm{~cd}$ & $18,73 \mathrm{~b}$ & $7,08 \mathrm{~cd}$ & $52,92 \mathrm{bc}$ & $36,67 \mathrm{c}$ & $89,59 \mathrm{bc}$ \\
\hline F6 & $0,212 \mathrm{~d}$ & $18,29 \mathrm{~b}$ & $6,97 \mathrm{~d}$ & $45,00 \mathrm{c}$ & $31,67 \mathrm{c}$ & $76,67 \mathrm{c}$ \\
\hline DMS & 0,04 & 3,87 & 1,66 & 15,11 & 7,25 & 27,44 \\
\hline
\end{tabular}

${ }^{*}$ Médias seguidas da mesma letra nas colunas não diferem entre si pelo teste de Tukey $(\mathrm{p}<0.05)$

Na comparação das médias da condutância estomática entre as frequências de irrigação, o tratamento $\mathrm{F} 2$, referente à frequência de irrigação de um dia, obteve a maior média, diferenciando-se estatisticamente $(\mathrm{p}<0,05)$ dos demais tratamentos com $0,477 \mathrm{~mol} \cdot \mathrm{m}^{-2} \cdot \mathrm{s}^{-1}$. Em contrapartida, a menor média foi obtida pelo tratamento F6 $\left(0,212 \mathrm{~mol} . \mathrm{m}^{-2} \cdot \mathrm{s}^{-1}\right)$, referente à frequência de irrigação realizada a cada cinco dias, que não se diferenciou estatisticamente $(\mathrm{p}<$ 
0,05) do tratamento F5. Os resultados demonstram que os efeitos das diferentes frequências de irrigação sobre a condutância estomática foram bem expressivos, o que condiz com Taiz \& Zeiger (2009) quando os autores relatam que a condutância estomática está frequentemente mais associada ao conteúdo de água no solo do que ao status hídrico da folha.

Oliveira et al. (2005), ressaltam que, durante o processo de absorção do $\mathrm{CO}_{2}$, as plantas, inevitavelmente, perdem água pelas folhas, isso ocorre, principalmente, através dos estômatos, que apresentam mecanismos para controlar o seu grau de abertura. Neste caso, o valor obtido no tratamento de menor frequência de irrigação (F6), é condizente com as explicações dos autores, que atribuem esse controle à condutância estomática foliar, que é frequentemente utilizada como indicador da deficiência hídrica.

De forma similar, Paiva et al. (2005) verificaram que o decréscimo na disponibilidade de água no solo ocasiona queda no potencial da água nas folhas das plantas, levando à perda de turgescência e à redução da condutância estomática. Devido à diminuição da condutância estomática a atividade fotoquímica é restringida de tal forma que, acidentalmente, ocorre a fotoinibição sob condições de acentuado déficit hídrico, tendo como consequência um fechamento quase que completo dos estômatos (Flexas et al., 2006).

Ressalta-se que as maiores frequências de irrigação, possibilitaram maior condutância estomática. Similarmente, Shimazaki et al., (2007) relatam que os estômatos regulam as trocas gasosas, aumentos na condutância estomática implicam influxos de $\mathrm{CO}_{2}$ no mesofilo foliar, possibilitando maiores taxas de assimilação de dióxido de carbono.

Analisando-se o efeito das frequências de irrigação para a variável fotossíntese, verifica-se que a frequência F2 apresentou maiores valores $\left(26,33 \mu \mathrm{mol} \cdot \mathrm{m}^{-2} \cdot \mathrm{s}^{-1}\right)$, assemelhando-se estatisticamente $(\mathrm{p}<0,05)$ aos tratamentos F1 e F3. Os menores valores de fotossíntese foram obtidos com tratamento F6 $\left(18,29 \mu \mathrm{mol} \cdot \mathrm{m}^{-2} \cdot \mathrm{s}^{-1}\right)$, referente à frequência de irrigação realizada a cada cinco dias, que não se diferenciou estatisticamente $(\mathrm{p}<0,05)$ dos tratamentos F4 e F5 (Tabela 4).

Estes menores valores da atividade fotossintética como decorrência da deficiência hídrica nos tratamentos submetidos às menores frequências de irrigação, indicam sensibilidade do meloeiro à menor disponibilidade hídrica no solo, uma vez que, sob condições de déficit hídrico, as plantas tendem a manter os estômatos abertos por um menor período, causando redução na assimilação de carbono e, consequentemente, implicando em redução sobre o metabolismo fotossintético (Pinheiro Neto et al., 2007).

Marenco \& Lopes (2009) salientam que a disponibilidade de água é o fator mais limitante da fotossíntese. Sendo assim, o menor valor de fotossíntese, obtido no tratamento F6 (18,29 $\left.\mu \mathrm{mol} . \mathrm{m}^{-2} . \mathrm{s}^{-1}\right)$ é condizente com as informações dos autores, ao ressaltarem ainda que, em condições de déficit hídrico há uma redução da fotossíntese devido ao fechamento dos estômatos que consequentemente, restringem a entrada de $\mathrm{CO}_{2}$ na folha.

Quanto à transpiração, nota-se que a frequência $\mathrm{F} 2$ apresentou maior valor médio $\left(9,71 \mathrm{mmol} \cdot \mathrm{m}^{-2} \cdot \mathrm{s}^{-1}\right)$, não diferindo, porém, dos tratamentos F1 e F3 (p < 0,05) (Tabela 4). Tais resultados sugerem que em condições de melhor disponibilidade hídrica, proporcionada pelas maiores frequências de irrigação, o meloeiro tende a apresentar maior transpiração, fato este evidenciado pelos valores de condutância estomática, uma vez que os estômatos são as principais vias de perda de água pela planta.

Os resultados constatados estão de acordo com as informações de Peixoto (2011) ao mencionar que a transpiração seria um mal necessário para as plantas realizarem as trocas gasosas, pois, a mesma via de entrada de $\mathrm{CO}_{2}$ serve como válvula de escape de vapor de água. Já o menor valor constatado foi obtido com o tratamento F6 $\left(6,97 \mathrm{mmol} . \mathrm{m}^{-2} \cdot \mathrm{s}^{-1}\right)$, referente à frequência de irrigação realizada a cada cinco dias, que não se diferenciou estatisticamente ( $\mathrm{p}<$ 0,05) dos tratamentos F5 e F4 (Tabela 4). 
Vale lembrar que esta situação é muito comum nas épocas mais quentes do ano, em que o excesso de radiação absorvida pelas culturas promove um incremento na temperatura da folha e no fluxo transpiratório (FAGAN et al., 2009). Quando esse incremento for maior que o fluxo hídrico da folha, os estômatos se fecham a fim de evitar uma desidratação excessiva do vegetal.

Percebe-se de uma maneira em geral, que o meloeiro sob condições de déficit hídrico altera seu mecanismo fisiológico, o qual pôde ser observado por meio da análise das trocas gasosas. Neste estudo, percebeu-se que as menores frequências de irrigação (F6 e F5) promoveram os menores valores dos parâmetros de fotossíntese, condutância estomática e transpiração avaliados no meloeiro, reafirmando-se a influência desvantajosa da falta de água no funcionamento do aparato fotossintético da planta. Resultados similares são apresentados por Suassuna et al. (2011) ao constatarem que em condições de déficit hídrico o meloeiro reduziu sua capacidade fotossintética.

Portanto, as assertivas reforçam a interdependência entre as variáveis analisadas, confirmando os resultados obtidos por Oliveira \& Carvalho (2010) ao constatarem que o aumento da condutância estomática levou a um aumento na transpiração, que por vez, gerou um aumento na fotossíntese.

No que diz respeito ao efeito das frequências de irrigação na produção de biomassa seca da parte aérea, verifica-se diferenças significativas entre os diferentes tratamentos, com redução da biomassa seca da planta (folhas, hastes e total) ao se reduzir a frequência de irrigação de duas vezes ao dia $(\mathrm{F} 1)$ para a frequência de cinco dias (F6). Os maiores valores médios de biomassa seca (folhas, hastes e total) obtidos foram, $96,67,59,58$ e 156,25 g.planta ${ }^{-1}$, respectivamente, dentro do tratamento $(\mathrm{F} 1)$, referente à frequência de irrigação de duas vezes ao dia, não diferindo, porém, estatisticamente $(\mathrm{p}<0,05)$ dos valores obtidos com as frequências (F2) e (F3), com exceção da variável matéria seca das hastes onde somente os tratamentos F1 e F2 não diferiram estatisticamente $(\mathrm{p}<0,05)$ entre si (Tabela 4$)$.

Dessa forma, os resultados sugerem que as frequências F1, F2 e F3 foram as que, possivel- mente, proporcionaram teores adequados de umidade no solo, promovendo baixa lixiviação e consequentemente maior absorção pela planta, o que poderia justificar os resultados obtidos. Corroborando com informações de Temóteo et al. (2010) ao verificarem aumento dos acúmulos de fitomassa seca da parte aérea do meloeiro devido ao efeito benéfico do manejo da irrigação.

Os menores valores médios de biomassa seca (folhas, hastes e total) obtidos foram, 45,00, 31,67 e 76,67 g.planta ${ }^{-1}$, respectivamente, dentro do tratamento (F6), referente à frequência de irrigação realizada a cada cinco dias, não diferindo, porém, estatisticamente $(\mathrm{p}<0,05)$ dos valores obtidos com a frequência (F5). Este menor desempenho pode ser atribuído em parte às condições de estresse hídrico na qual as plantas foram expostas durante o período entre duas irrigações, ocasionando uma diminuição no crescimento da planta, uma vez que, em condições de déficit hídrico, as plantas tendem a ter seu desenvolvimento comprometido. Estes resultados estão condizentes com informações de Marouelli \& Silva (2005) ao verificarem que em menores frequências de irrigação a fitomassa seca da parte aérea do tomateiro é afetada negativamente. Tomaz et al. (2008) também encontraram redução na matéria seca da parte aérea do meloeiro em condições de pouca disponibilidade hídrica.

A biomassa seca da folha de 96,67 g.planta ${ }^{-1}$ correspondeu a $61,8 \%$ da biomassa seca da parte aérea (folhas + hastes). Resultados semelhantes foram encontrados por Ferraz et al. (2011) ao constatarem que a massa seca foliar correspondeu a $69,05 \%$ da massa seca da parte aérea (folhas e ramos); outrossim, Figueirêdo (2008) encontrou valor médio da massa seca das folhas de 115,13 g.planta ${ }^{-1}$, correspondente a $69,95 \%$ da massa seca da parte aérea do meloeiro.

Quanto à matéria seca das hastes, Ferraz et al. (2011), constataram diferenças significativas na matéria seca do caule sob diferentes condições de disponibilidade hídrica. Os autores registraram um ganho de $47,8 \%$ promovido pelo aumento da umidade no solo quando comparado à condição de menor disponibilidade hídrica. $\mathrm{Na}$ 
presente pesquisa, entre os tratamentos F1 e F6, o incremento na biomassa seca da haste promovido foi de $88,12 \%$, quando os tratamentos variaram da menor para a maior frequência de irrigação avaliadas (Tabela 4).

A biomassa seca total da cultura do meloeiro, avaliada pela massa seca da parte aérea sem os frutos, foi maximizada para o tratamento F1, correspondente a frequência de irrigação diária realizada em dois períodos, manhã e tarde (Tabela 4). Quando as irrigações foram realizadas com intervalo de 5 dias (referente a frequência de irrigação submetida ao tratamento F6), ocorreu uma redução na matéria seca da planta de 50,93\% em relação à máxima, o que se deve à maior redução no crescimento das plantas, uma vez que, sob tal tratamento as plantas apresentaram menor crescimento vegetativo.

Figueirêdo (2008) constataram valor médio para a matéria seca da parte aérea de $207,75 \mathrm{~g}$ planta $^{-1}$; Gurgel et al. (2010) encontraram valor médio de $151,58 \mathrm{~g}_{\text {planta }}{ }^{-1}$. Confrontando os resultados constatados entre os autores com relação ao maior valor médio obtido nesta pesquisa, pode-se dizer que tais respostas devem estar relacionadas com diferentes fatores como genótipo, clima, solo, época de plantio e condições de manejo.
Duarte \& Peil (2010) salientam que, modificações na força das fontes, através de uma alteração na disponibilidade hídrica, afetariam indiretamente a distribuição de matéria seca entre os órgãos da planta. Assim, a redução da força de fonte das plantas nas frequências de irrigação mais baixas reduziria a disponibilidade de fotoassimilados para o crescimento da fração vegetativa, e diminuiria consequentemente, a disponibilidade para o compartimento generativo, o que levaria a uma redução na proporção de matéria seca alocada para este.

Portanto, pelo maior período de estresse hídrico que ocorre na menor frequência de irrigação, a redução da força de fonte e, consequentemente, da disponibilidade de fotoassimilados, reduziram a proporção com que estes são destinados aos frutos, em benefício dos órgãos vegetativos (folhas e hastes), havendo assim, um maior estímulo ao crescimento vegetativo da planta.

$\mathrm{Na}$ Tabela 5 estão apresentados os valores médios de condutância estomática (CES), fotossíntese (FOT), transpiração (TRA), matéria seca das folhas (MSF), matéria seca das hastes (MSH) e matéria seca total (MST) em função do parcelamento da adubação nitrogenada em diferentes épocas.

Tabela 5 - Condutância estomática (CES), fotossíntese (FOT), transpiração (TRA), matéria seca das folhas (MSF), matéria seca das hastes (MSH) e matéria seca total (MST) do meloeiro submetido ao parcelamento da adubação nitrogenada em diferentes épocas*

\begin{tabular}{ccccccc}
\hline \multirow{2}{*}{$\begin{array}{c}\text { Parcelamento } \\
\text { do Nitrogênio }\end{array}$} & $\begin{array}{c}\text { CES } \\
\left(\mathrm{mol} \cdot \mathrm{m}^{-2} \cdot \mathrm{s}^{-1}\right)\end{array}$ & $\begin{array}{c}\text { FOT } \\
\left(\mu \mathrm{mol} \cdot \mathrm{m}^{-2} \cdot \mathrm{s}^{-1}\right)\end{array}$ & $\begin{array}{c}\text { TRA } \\
\left(\mathrm{mmol} \cdot \mathrm{m}^{-2} \cdot \mathrm{s}^{-1}\right)\end{array}$ & \multicolumn{3}{c}{$\left(\mathrm{g} \cdot \mathrm{planta}^{-1}\right)$} \\
\cline { 5 - 7 } N1 (0-100-0-0) & $0,285 \mathrm{~b}$ & $22,11 \mathrm{a}$ & $7,42 \mathrm{c}$ & $58,89 \mathrm{c}$ & $34,17 \mathrm{~d}$ & $93,06 \mathrm{~d}$ \\
N2 (30-70-0-0) & $0,321 \mathrm{ab}$ & $22,95 \mathrm{a}$ & $8,16 \mathrm{~b}$ & $70,00 \mathrm{~b}$ & $41,67 \mathrm{c}$ & $111,67 \mathrm{c}$ \\
N3 (30-30-40-0) & $0,336 \mathrm{ab}$ & $21,82 \mathrm{a}$ & $8,43 \mathrm{~b}$ & $73,33 \mathrm{~b}$ & $48,89 \mathrm{~b}$ & $122,22 \mathrm{~b}$ \\
N4 (20-30-30-20) & $0,369 \mathrm{a}$ & $23,26 \mathrm{a}$ & $9,23 \mathrm{a}$ & $90,00 \mathrm{a}$ & $59,72 \mathrm{a}$ & $149,72 \mathrm{a}$ \\
\hline DMS & 0,05 & 2,36 & 0,54 & 7,39 & 6,72 & 11,01 \\
\hline
\end{tabular}

${ }^{*}$ Médias seguidas da mesma letra nas colunas não diferem entre si pelo teste de Tukey $(\mathrm{p}<0.05)$

Nota-se na comparação dos resultados que os índices fisiológicos obtiveram respostas semelhantes ao manejo da adubação nitrogenada, com exceção da fotossíntese que não apresentou diferença significativa entre os tratamentos. Apesar de não ter sido observado diferenças significativas para esta variável, o tratamento onde o $\mathrm{N}$ foi aplicado até 50 DAS (20-30-30-20), apresentou maior valor médio com 23,26 $\mu \mathrm{mol} . \mathrm{m}^{-2}$. $\mathrm{s}^{-1}$. Este resultado sugere que o parcelamento da adubação nitrogenada pode melhorar os níveis de $\mathrm{N}$ nas plantas, ou a capacidade que elas têm em acumulá-lo em seus tecidos foliares, o que provavelmente influenciou 
na fotossíntese.

Cabrera-Bosquet et al. (2009), afirmam que esse efeito do nitrogênio, que estimula a fotossíntese, é decorrente da maior incitação à atividade enzimática e da maior síntese da enzima ribulose - 1,5 - bisfosfato - carboxilaseoxigenase, responsável pela fotossíntese, entre outras, associado ao efeito também sobre a transpiração, que favorece a fotossíntese.

Em relação à condutância estomática notase que o tratamento onde o $\mathrm{N}$ foi aplicado até 50 DAS (20-30-30-20), apresentou maior valor médio com $0,369 \mathrm{~mol} \cdot \mathrm{m}^{-2} \cdot \mathrm{s}^{-1}$, mostrando o maior fluxo de trocas gasosas da planta com a atmosfera no maior parcelamento da adubação nitrogenada. Já o menor valor de condutância estomática foi constatado no tratamento onde toda a cobertura do $\mathrm{N}$ foi aplicada aos 20 DAS (0-100-0-0), com valor médio observado de $0,285 \mathrm{~mol} \cdot \mathrm{m}^{-2} \cdot \mathrm{s}^{-1}$ (Tabela 5). Tal resultado pode ser atribuído ao suprimento inadequado de $\mathrm{N}$ a cultura na época em que a planta menos exige o nutriente, afetando desta forma, o desenvolvimento da planta, ficando parte do $\mathrm{N}$ susceptível a lixiviação e limitando a sua absorção na fase onde o crescimento da planta demanda de maior aporte de nutrientes, próximo à floração e crescimento e maturação dos frutos (Oliveira et al., 2009).

O resultado superior para condutância estomática na aplicação do $\mathrm{N}$ até 50 DAS (2030-30-20) pode ter sido reflexo da maior fitomassa seca da parte aérea, com elevação da demanda hídrica, refletindo em uma maior abertura estomática como mecanismo para atender a absorção de $\mathrm{CO}_{2}$ do meio externo e regular a temperatura da folha através da transpiração.

Quanto à transpiração, verifica-se novamente que o $\mathrm{N}$ aplicado até 50 DAS (20-30-3020 ), apresentou maior valor médio com 9,23 mmol. $\mathrm{m}^{-2} \cdot \mathrm{s}^{-1}$. Tal fato pode ter ocorrido devido à elevação na produção de biomassa até tal época, levando ao aumento da fotossíntese líquida do dossel e consequentemente da demanda hídrica das plantas com maior absorção de água pelas raízes (Lopes et al., 2011). Já o menor valor de transpiração foi de $7,42 \mathrm{mmol} \cdot \mathrm{m}^{-2} \cdot \mathrm{s}^{-1}$ constatado no tratamento onde a aplicação total de cobertura do $\mathrm{N}$ foi realizada aos 20 DAS (0-100-0-0).

Percebe-se desta forma, que o parcelamento da adubação nitrogenada até 50 DAS (20-30-30-20) afetou de forma positiva o aumento da condutância estomática e transpiração quando comparada a aplicação total do $\mathrm{N}$ em cobertura aos 20 DAS (0-100-0-0), e que os parâmetros avaliados demonstraram estreita relação. Resultados semelhantes são apresentados por Oliveira \& Carvalho (2010) ao constatarem correlação positiva entre a condutância estomática e a transpiração. Os resultados confirmam também as informações de Taiz \& Zeiger (2009) ao ressaltarem que o aumento da condutância estomática está relacionado a uma maior abertura estomática o que consequentemente ocasiona uma maior taxa de transpiração. Os últimos autores mencionaram ainda que o suprimento inadequado dos elementos essenciais às plantas causa distúrbios nos processos metabólicos o que resulta em funcionamento anormal das plantas.

De acordo com os dados expressos na Tabela 5, observou-se que o manejo da adubação nitrogenada exerceu efeito significativo $(p<0,05)$ sobre a matéria seca do meloeiro nas suas diferentes partes (folhas, hastes e total). Os maiores valores médios encontrados da matéria seca das folhas $\left(90,00\right.$ g.planta $\left.{ }^{-1}\right)$, matéria seca das hastes $\left(59,72 \mathrm{~g}\right.$ planta $\left.^{-1}\right)$ e matéria seca total $\left(149,72\right.$ g.planta $\left.{ }^{-1}\right)$ foram obtidos com o tratamento N4 (20-30-30-20), referente a aplicação em cobertura do $\mathrm{N}$ até 50 DAS.

Os resultados demonstrados acima podem ser explicados pelo fato de que, quando aplicado parceladamente, o $\mathrm{N}$ é fornecido à planta, nos seus diferentes estádios de desenvolvimento, na época em que sua absorção é mais exigida, corroborando com as informações de Temóteo et al. (2010), ao mencionarem que a absorção de nutrientes difere de acordo com a fase de desenvolvimento da planta, intensificando-se com o florescimento, a formação e crescimento dos frutos.

Silva \& Silva (2002) também comentaram que a aplicação parcelada limita ou reduz o potencial para perda do $\mathrm{N}$ por lixiviação ou desnitrificação, pois além do $\mathrm{N}$ permanecer no solo por um período menor de tempo, nessa 
ocasião já existe um sistema radicular ativo em crescimento, para absorção do $\mathrm{N}$ aplicado.

De acordo com os dados expressos na Tabela 5, observou-se que o manejo da adubação nitrogenada exerceu efeito significativo $(p<0,05)$ sobre a matéria seca total, onde o maior valor médio encontrado foi de 149,72 g.planta ${ }^{-1}$ obtido com o tratamento N4 (20-30-30-20), referente à aplicação em cobertura do $\mathrm{N}$ até $50 \mathrm{DAS}$. Tais resultados talvez tenham como causa o fato de que, quando aplicado parceladamente, o $\mathrm{N}$ é fornecido à planta, nos seus diferentes estádios de desenvolvimento, na época em que sua absorção é mais exigida, corroborando com as informações de Temóteo et al. (2010), ao mencionarem que a absorção de nutrientes difere de acordo com a fase de desenvolvimento da planta, intensificando-se com o florescimento, a formação e crescimento dos frutos.

Os menores valores médios encontrados da matéria seca das folhas $\left(58,89\right.$ g.planta $\left.{ }^{-1}\right)$, matéria seca das hastes $\left(34,17\right.$ g.planta $\left.{ }^{-1}\right)$ e matéria seca total $\left(93,06\right.$ g.planta $\left.{ }^{-1}\right)$ foram obtidos com o tratamento N1 (0-100-0-0). Os resultados sugerem que quando o nitrogênio é aplicado precocemente na cultura do melão a matéria seca da planta é prejudicada pela falta deste nutriente nas fases do ciclo onde ela é mais exigida pela cultura, confirmando os resultados de Temóteo et al. (2010), que avaliando a influência da adubação nitrogenada na acumulação da fitomassa seca da parte aérea verificou que a falta de nitrogênio proporcionou diminuição no acúmulo de fitomassa seca.

Resultados semelhantes foram observados por Silva Júnior et al. (2006) e Silva Júnior et al. (2010) em outras pesquisas com meloeiro.

Vale ressaltar que, como no presente trabalho o experimento foi conduzido com irrigação, a água deve ter contribuído para perdas do nutriente, especialmente quando ele foi aplicado em grandes proporções como é o caso dos tratamentos N1 (0-100-0-0) e N2 (30-70-0$0)$, tratamentos que receberam as maiores proporções da adubação nitrogenada até 20 DAS.

De acordo com Taiz \& Zeiger (2009), a célula vegetal apresenta elevada capacidade de estocagem de $\mathrm{N}$ no vacúolo, no entanto, essas quantidades quando comparadas com a demanda para o crescimento são consideradas pequenas. Desta forma, o manejo ideal do $\mathrm{N}$ seria aquele capaz de ajustar as doses de adubação de acordo com a produção de biomatéria da cultura nas diferentes épocas e fases do seu ciclo de crescimento e desenvolvimento.

\section{CONCLUSÕES}

A frequência de irrigação e o parcelamento da adubação nitrogenada afeta os componentes fisiológicas do meloeiro, sendo os maiores valores de fotossíntese, condutância estomática e transpiração obtidos com a frequência de irrigação diária (F2) e com a aplicação em cobertura do $\mathrm{N}$ até $50 \mathrm{DAS}$; proporcionando, também, melhor desenvolvimento vegetativo à cultura, quanto a matéria seca em suas diferentes partes (folhas, hastes e total).

$\mathrm{O}$ déficit hídrico ocasionado entre irrigações, na menor frequência estudada (F6), propiciou menores valores em todas as variáveis analisadas, assim como a aplicação total aos 20 DAS de $\mathrm{N}$ em cobertura.

\section{LITERATURA CITADA}

Cabrera-Bosquet, L.; Albrizio, R.; Araus, J.L. Nogués, S. Photosynthetic capacity of fieldgrown durum wheat under different $\mathrm{N}$ availabilities: A comparative study from leaf to canopy. Environmental and Experimental Botany, v.67, n.1, p.145-152, 2009. http://www.sciencedirect.com/science/journal/00 988472/67/1 10 jan. 2012.

Duarte, T. S.; Peil, R. M. N. Relações fonte:dreno e crescimento vegetativo do meloeiro. Horticultura Brasileira, v. 28, n. 3, p. 271-276, 2010. < http://dx.doi.org/10.1590/ S0102-05362010000300005 22 dez. 2011.

Embrapa Solos. Centro Nacional de Pesquisa de Solos (Rio de Janeiro). Sistema brasileiro de classificação de solos. Brasília: Sistema de produção de Informação - SPI, 1999. 412p.

Fagan, E. B.; Petter, S. L.; Simon, J.; Borcioni, 
E.; Luz, J. L.; Manfron, P. A. Eficiência do uso de água do meloeiro hidropônico. Bioscience Journal, v. 25, n. 2, p. 37-45, 2009.

Ferraz, R. L. de S.; Melo, A. S. de; Ferreira, R. de S.; Dutra, A. F.; Figueredo, L. F. de. Aspectos morfofisiológicos, rendimento e eficiência no uso da água do meloeiro "Gália" em ambiente protegido. Revista Ciência Agronômica, v. 42, n. 4, p. 957-964, 2011.

Figueirêdo, V. B. Evapotranspiração, crescimento e produção da melancia e melão irrigados com águas de diferentes salinidades. 2008. 104p. Tese (Doutorado) - Universidade Estadual Paulista, Faculdade de Ciências Agronômicas, Botucatu. 2008.

Flexas, J.; Bota, J.; Galmés, J.; Medrano, H.; Ribas-Carbo, M. Keeping a positive carbon balance under adverse conditions: responses of photosynthesis and respiration to water stress. Physiologia Plantarum, v.127, p.343-352, 2006. $<$ http://onlinelibrary.wiley.com/doi/10.1111/ppl. 2006.127.issue-3/issuetoc> 18 dez 2011.

Gurgel, M. T.; Uyeda, C. A.; Gheyi, H. R.; Oliveira, F. H. T. de; Fernandes, P. D.; Silva, F. V. da. Crescimento de meloeiro sob estresse salino e doses de potássio. Revista Brasileira de Engenharia Agrícola e Ambiental, v.14, n.1, p.310, 2010.

Lopes, M. N.; Pompeu, R. C. F. F.; Cândido, M. J. D.; Lacerda, C. F. de.; Silva, R. G. da.; Fernandes, F. R. B. Growth index in massai grass under different levels of nitrogen fertilization. Revista Brasileira de Zootecnia, v.40, n.12, p.2666-2672, 2011.

Marenco, R. A.; Lopes, N. F. Fisiologia vegetal: fotossíntese, respiração, relações hídricas e nutrição mineral. 3. ed., atual. ampl. - Viçosa, MG, Ed. UFV, 2009.

Marouelli, W. A.; Silva, W. L. de C. Frequência de irrigação por gotejamento durante o estádio vegetativo do tomateiro para processamento industrial. Pesquisa Agropecuária Brasileira, v. 40, n. 7, p. 661-666, 2005.

Marouelli, W.A.; Silva, W.L.C. e; Silva, H.R. da. Manejo da irrigação em hortaliças. Brasília: Embrapa-SPI, 1994. 60p.

Melo, A. S. de,; Suassuna, J. F.; Fernandes, P. D.; Brito, M. E. B.; Suassuna, A. F.; Aguiar Netto, A. O. Crescimento vegetativo, resistência estomática, eficiência fotossintética e rendimento do fruto da melancieira em diferentes níveis de água. Acta Scientiarum. Agronomy, v. 32, n. 1, p. 73-79, 2010. <http://periodicos.uem.br/ ojs/index.php/ActaSciAgron/article/view/2136> 24 fev. 2012.

Oliveira, P. C.; Carvalho, C. J. R. Respostas ecofisiológicas por espécies arbóreas acumuladoras de fósforo na Amazônia. Holos, ano 26, v. 1, 2010.

Oliveira, F. de A. de.; Medeiros, J. F. de.; Lima, C. J. G. de S. Dutra, I.; Oliveira, M. K. T. de.; Amâncio, M. das G. Acúmulo e partição de matéria seca, nitrogênio e potássio pelo meloeiro fertirrigado. Bioscience Journal, v. 25, n. 3, p. 24-31, 2009.

Oliveira, A. D. de, Fernandes, E. J., Rodrigues, T. J. D. Condutância estomática como indicador de estresse hídrico em feijão. Engenharia Agrícola, v.25, n.1, p.86-95, 2005.

Paiva, A. S.; Fernandes, E. J.; Rodrigues, T. J. D.; Turco, J. E. P. Condutância estomática em folhas de feijoeiro submetido a diferentes regimes de irrigação. Engenharia Agrícola, v.25, n.1, p.161-169, 2005.

Peixoto, C. P. Curso de fisiologia vegetal, Cruz das Almas, BA. 2011. 177f.; il.

Pinheiro Neto, L. G.; Viana, T. V. A.; Azevedo, B. M.; Freitas, J. A. D.; Sousa, V. F. Produção e qualidade dos frutos de meloeiro submetido a redução hídrica na fase final do ciclo. Irriga, v. 12, n. 01, p. 54-62, 2007. 
Shimazaki, K.; Doi, M.; Assmann, S. M.; Kinoshita, T. Light regulation of stomatal movement. Annual Review of Plant Biology, v. 58, n. 1, p. 219-247, 2007.

lva, B. B. da.; Ferreira, J. A. da S.; Rao, T. V. R.; Silva, V. de P. R. da. Características de parâmetros fisiológicos e de crescimento do meloeiro irrigado. Revista Brasileira de Agrometeorologia, v. 13, n. 1, p. 45-52, 2005.

Silva, F. de A. S. ASSISTAT versão 7.6 beta (2012). Campina Grande-PB: Assistência Estatística, Departamento de Engenharia Agrícola do CTRN - Universidade Federal de Campina Grande, Campus de Campina. Disponível em: < http://www.assistat.com/index.html >. Acesso em: 20 jul. 2012.

Silva, P. S. L.; Silva, P. I. B. Efeitos de épocas de aplicação de nitrogênio no rendimento de grãos do milho. Pesquisa Agropecuária Brasileira, v. 37, n. 8, p. 1057-1064, 2002.

Silva Júnior, M. J. da.; Medeiros, J. F. de.; Oliveira, F. H. T. de.; Dutra, I. Acúmulo de matéria seca e absorção de nutrientes pelo meloeiro "pele-de-sapo". Revista Brasileira de Engenharia Agrícola e Ambiental, v. 10, n. 2, p. 364-368, 2006.

Silva Júnior, M. J. da.; Duarte, S. N.; Oliveira, F. de A. de.; Medeiros, J. F. de.; Dutra, I. Resposta do meloeiro à fertigação controlada através de íons da solução do solo: Desenvolvimento vegetativo. Revista Brasileira de Engenharia Agrícola e Ambiental, v. 14, n. 7, p. 715-722, 2010.

Snyder, R. L. Equation for evaporation pan to evapotranspiration conversions. Journal of Irrigation and Drainage, v. 118, n. 6, p. 977-980, 1992.

Suassuna, J. F.; Melo, A. S. de.; Costa, F. S.; Fernandes, P. D.; Ferreira, R. S.; Sousa, M. S. da S. Eficiência fotoquímica e produtividade de frutos de meloeiro cultivado sob diferentes lâminas de irrigação. Ciências Agrárias, v. 32, n. 4, p. 1251-1262, 2011. <http://www.uel.br/revistas/uel/index.php/semag rarias/article/view/4793/9038> 15 fev. 2012.

Taiz, L.; Zeiger, E. Fisiologia vegetal. 4.ed. Porto Alegre: Artmed, 2009. 819p.

Temóteo, A. da S.; Medeiros, J. F. de.; Dutra, I. Oliveira, F. A. de; Crescimento e acúmulo de nitrogênio e potássio pelo melão pele de sapo fertirrigado. Irriga, v. 15, n. 3, p. 275-281, 2010.

Tomaz, H. V. de Q.; Porto Filho, F. de Q.; Medeiros, J. F. de; Dutra, I.; Queiroz, R. F. Crescimento do meloeiro sob diferentes lâminas de água e níveis de nitrogênio e potássio. Caatinga, v.21, n.3, p.174-178, 2008. 